\title{
The effect of monetary policy on real house price growth in South Africa: A factor-augmented vector autoregression (FAVAR) approach
}

\author{
Rangan Gupta ${ }^{a}$, Marius Jurgilas ${ }^{c}$ and Alain Kabundi ${ }^{b}$ \\ ${ }^{\mathrm{a} D e p a r t m e n t ~ o f ~ E c o n o m i c s, ~ U n i v e r s i t y ~ o f ~ P r e t o r i a, ~ P r e t o r i a, ~ 0002, ~ S o u t h ~ A f r i c a ~}$ \\ ${ }^{\mathrm{b}}$ University of Johannesburg, Department of Economics, Johannesburg, 2006, South Africa \\ ${ }^{\mathrm{c}}$ Economist, Financial Stability Directorate, Bank of England, Threadneedle Street, London, \\ EC2R 8AH, United Kingdom
}

\begin{abstract}
This paper assesses the impact of monetary policy on real house price growth in South Africa using a factor-augmented vector autoregression (FAVAR), estimated using a large data set comprising of 246 quarterly series over the period 1980:01 to 2006:04. The results based on the impulse response functions indicate that, in general, house price inflation responds negatively to monetary policy shock, but the responses are heterogeneous across the middle-, luxury- and affordable-segments of the housing market. The luxury-, large-middle- and medium-middlesegments are found to respond much more than the small-middle- and the affordable-segments of the housing market. More importantly, we find no evidence of the home price puzzle, observed previously by other studies that analyzed house prices using small-scale models. We put this down to the benefit gained from using a large information set.
\end{abstract}

Keywords: Monetary policy; Real house price growth; FAVAR

\section{Introduction}

The recent global economic downturn attributed to the sub-prime crisis in the US with rapid contagion worldwide, particularly in the housing sector, has attracted the attention of academics, policymakers, and economic agents at large. Stock and Watson (2003) pointed out that housing prices are leading indicators for real activity, inflation, or both, and, hence, can serve as an indicator as to where the real economy is heading. Evidence in the recent literature, for example, (Iacoviello, 2005), (Case et al., 2005), (Iacoviello and Neri, 2008), (Vargas-Silva, 2008a) and (Vargas-Silva, 2008b) amongst others, show a strong link between the housing market and economic activity in the US. Moreover, the recent emergence of boom-bust cycles in house prices have been an issue of concern for policy markers (Borio et al., 1994, Bernanke and Gertler, 1995 and Bernanke and Gertler, 1999), since the bust of the house price bubble is always followed by significant contractions in the real economy (Iacoviello and Neri, 2008). Given this, it is crucial for central banks to analyze thoroughly the effects of monetary policy on asset prices 
in general, and real estate in particular, which, in turn, would lead to the understanding of effects of policy on the economy at large.

In this backdrop, this paper assesses the impact of monetary policy shocks on real house price growth, i.e., the growth rate of the ratio of nominal house price to the Consumer Price Index (CPI), for the luxury, large-, medium- and small-middle-segments and affordable housing for the South African economy ${ }^{1}$ by exploiting a data-rich environment that includes 246 quarterly series, such as income, interest rates, construction costs, labour market variables, stock prices, industrial production, and consumer confidence index over the period 1980:01 to 2006:04. For this purpose, the framework used in this paper is a factor-augmented vector autoregression (FAVAR) model proposed by Bernanke et al. (2005). As Bernanke et al. (2005) indicate, monetary authorities analyze literally thousands of variables in their decision-making process, hence, it is aberrant for anyone, who tries to mimic actions of a central bank, to ignore this fact. Furthermore, the recent literature (Stock and Watson, 2004 ; Rapach and Strauss, 2007 ; Rapach and Strauss, 2009 ; Das et al., 2008 ; Das et al., 2009 and Das et al., forthcoming) provide evidence of the fact that numerous economic variables are potential predictors of house price growth. Intuitively, the FAVAR approach boils down to extracting a few latent common factors from a large matrix of many economic variables, with the former maintaining the same information contained in the original data set without running into the risk of the degrees of freedom problem. ${ }^{2}$ Note, the motivation to use the three major segments of the housing market, with the middle-segment subdivided further into three categories based on sizes, and not just the aggregate housing market, emanates from the fact that the market for different house-types are found to behave differently (Burger and van Rensburg, 2008). Clearly then, the impact of monetary policy on the different segments of the South African housing market is less likely to be homogenous. This is more so, when one realizes that different housing segments cater to different income-groups.

To the best of our knowledge, this is the first study to analyze the effect of monetary policy on real house price growth in South Africa using a FAVAR. The only other paper that deals with the impact of monetary policy on the South African housing market is that by Kasai and Gupta (2008). The authors investigated the effectiveness of monetary policy on house prices in South Africa, before and after financial liberalization, with financial liberalization being identified with the recommendations of the De Kock Commission (1985). Using both impulse response and variance decomposition analysis performed on three-variable structural VARs (SVARs), comprising of the growth rate of the real GDP, house price inflation and the Treasury Bill rate, estimated separately on the three categories of the middle-segment of the housing market, the authors found that irrespective of house sizes, during the period of financial liberalization, interest rate shocks have had relatively stronger effects on house price inflation. But, given that the size of these effects were nearly negligible, the result seems to indicate that house prices are exogenous, and, at least, are not driven by monetary policy shocks.

Though insightful, the paper by Kasai and Gupta (2008), just like (Iacoviello, 2002), (McCarthy and Peach, 2002), (Iacoviello and Minetti, 2003) and (Iacoviello and Minetti, 2008), ${ }^{3}$ VargasSilva (2008a), is based on a small-scale model, which, in turn, limits it to only three variables. In fact, all the other studies, being based on either reduced-form Vector Autoregressive (VAR), Vector Error Correction (VEC), SVAR or DSGE models, could handle at most 8 to 12 variables 
only. Arguably, and as indicated above, there are a large number of variables that affects monetary policy and the housing market, and not including them often leads to puzzling results, for example the home price puzzle $e^{4}$ in (McCarthy and Peach, 2002) and (Kasai and Gupta, 2008), ${ }^{5}$ which are not in line with economic theory due to the small information set ([Sims, 1992] and [Walsh, 2000]). Moreover, in these studies, the authors often arbitrarily accept specific variables as the counterparts of the theoretical constructs (for example the gross domestic product as a measure of economic activity or the first difference of the logarithm transformed consumer price index as a measure of inflation), which, in turn, may not be perfectly represented by the selected variables. In addition, previous studies can only obtain the impulse response functions (IRFs) from those few variables included in the model, implying that in each VAR, VECM, SVAR or DSGE, the IRFs are typically obtained with respect to only one variable related to the housing market. Given its econometric construct, the FAVAR model addresses all these problems.

The remainder of the paper is organized as follows: Section 2 briefly discusses the FAVAR framework, while, Section 3 discusses the data and the identification structure. Section 4 reports and analyzes the impulse response functions, and Section 5 concludes.

\section{The FAVAR ${ }^{6}$}

Let $Y_{t}$ be a $M \times 1$ vector of observable economic variable assumed to drive the dynamics of the economy. In the standard approach, we would proceed by estimating a structural VAR (SVAR), or other forms of multivariate time series model using data for only $Y_{t}$. In many cases, however, additional economic information that cannot be fully captured by $Y_{t}$ may be required to model appropriately the dynamics of these series. Assume that $F_{t}$ is a $K \times 1$ vector of unobserved factors, with $K$ being small, that summarizes additional important information not fully captured by $Y_{t .}$. Note $F_{t}$ can also represent theoretical concepts such as price pressures, credit conditions, or even economic activity that are a combination of economic variables which cannot be represented by one particular series. Assume that the joint dynamics of $\left(F_{t}, Y_{t}\right)$ are given by the following equation:

$$
\left[\begin{array}{l}
F_{t} \\
Y_{t}
\end{array}\right]=\Phi(L)\left[\begin{array}{l}
F_{t-1} \\
Y_{t-1}
\end{array}\right]+v_{t}
$$

where $\Phi(L)$ is a conformable lag polynomial of finite order $p$ and $v_{t}$ is the error term with zero mean and a covariance matrix $Q$.

Eq. (1) is a standard VAR in $\left(F_{t}, Y_{t}\right)$ and nests a standard VAR in $Y_{t}$, if the terms of $\Phi(L)$ that relate to $Y_{t}$ to $F_{t-1}$ are equal to zero. In its current form we refer to Eq. (1) as a factor-augmented vector autoregression (FAVAR). Clearly the system defined by Eq. (1) helps in assessing the marginal contribution of the additional information content of $F_{t}$. Moreover, if Eq. (1) is estimated without the factors then we would obtain biased estimates of coefficients for both the VAR and the impulse responses. 
However, the difficulty here is that the vector of factors $F_{t}$ is unobserved, which means that the model cannot be estimated based on standard econometric techniques, such as the ordinary least squares (OLS). The proper estimation of the model entails the use of factor analysis, as proposed by Stock and Watson (1998). For this purpose, we interpret the factors as summarizing information contained in a large panel of economic time series. Given this, we can hope to infer about the factors from these variables. Let $X_{t}$ be a $N \times 1$ vector of informational variables, where $N$ is large, such that $N>>K+M$. Assume $X_{t}$ is related to both the observed variables $Y_{t}$ and unobserved factors $F_{t}$ as follows:

$X_{t}^{\prime}=\Lambda^{f} F_{t}^{\prime}+\Lambda^{y} Y_{t}^{\prime}+e_{t}^{\prime}$

where $\Lambda^{f}$ is a $N \times K$ matrix of factor loadings, $\Lambda^{y}$ is $N \times M$, and $e_{t}$ is a $N \times 1$ vector of the error term, which, in turn, is assumed to be weakly correlated with mean zero. In essence, $Y_{t}$ and $F_{t}$ are common forces that drive the dynamics of $X_{t}$. Note, it is not restrictive to assume in principle that $X_{t}$ is dependent only on the current values of $F_{t}$ and not its lagged value, since the factors can always be interpreted to capture arbitrary lags of some fundamental factors. Excluding the observable factors from Eq. (2), we have what Stock and Watson (1998) refer to as a dynamic factor model (DFM).

The estimation procedure consists of a two-step principal components approach proposed by Bernanke et al. (2005), which, in turn, provides a non-parametric way of uncovering the space spanned by the common components, $C_{t}=\left(F_{t}^{\prime}, Y_{t}^{\prime}\right)$. In the first step, the common components, $C_{t}$ are estimated using the first $K+M$ principal components of $X_{t}$, defined as $\hat{C}_{t}$. Note the estimation of the first step does not use the fact that $Y_{t}$ is observed. Stock and Watson (2002) demonstrates that with a large $N$ and if the number of principal components is at least as large as the number of factors, the principal components can consistently recover the space spanned by

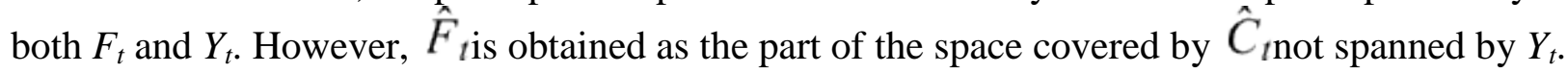
In the second step, the FAVAR model (1) is estimated via standard methods with $F_{t}$ replaced by $\hat{F}_{t}$. As discussed by Stock and Watson (2002), this approach imposes fewer distributional assumptions, when compared to the alternative single-step Bayesian likelihood approach, and also allows for some degree of cross-correlation in the idiosyncratic error term $e_{t}$, besides being computationally simple and easy to implement. In the second step, the two-step approach, however, implies the presence of "generated regressors", and given this uncertainty in the factor estimation, we need to implement a bootstrap procedure to obtain accurate confidence intervals. In this regard, we follow Kilian (1998).

Next, we need to discuss the identification of the model described by Eqs. (1) and (2). In other words, we need to impose restrictions necessary to identify uniquely the factors and the associated loadings. Given that, in two-step estimation method, based on principal components, the factors are obtained entirely from the observation Eq. (2), identification of the factors is standard. Formally, we can choose either to restrict loadings such that: $\Lambda^{f^{\prime}} \Lambda^{f} / N=I$ or the factors to ensure that $F^{\prime} F / T=I$. Either way we obtain the same common component $F \Lambda^{f^{\prime}}$ and the same factor space. Following Bernanke et al. (2005), we impose the factor restriction to obtain $\hat{F}=\sqrt{T} \hat{Z}$, where the $Z$ are the eigenvectors corresponding to the $K$ largest eigenvalues of 
$X X^{\prime}$, ordered in a descending fashion. This approach allows us to identify the factors against any rotations.

A separate identification issue concerns the identification of innovations in the VAR part of the model, which in our case involves the identification of the monetary policy innovations. ${ }^{7}$ This is what we discuss next. In this paper, we assume that the only observable factor is the nominal 91 days Treasury Bill rate $\left(T B_{t}\right)$, i.e., the only variable included in $Y_{t}$ is $T B_{t}$. Thus, we treat the 91 days Treasury Bill rate as a factor and interpret it as the monetary policy instrument. This can be motivated on the presumption that monetary policy has pervasive effect on the economy. It must be noted that macroeconomic data is generally subject to multiple rounds of revisions and are never free of measurement error. But the 91 days Treasury Bill rate should not suffer from measurement error issues, since this would then imply the presence of an idiosyncratic component in the monetary policy instrument. With theoretical concepts not necessarily aligned with specific variables in the data, real activity and inflation can be treated as unobserved in the empirical analysis. Also treating these variables as latent factors allows one to acknowledge the issues with real-time data. Finally, speaking specifically, there is no evidence in the history of monetary policy of South Africa that could suggest that the South African Reserve Bank (SARB) was controlling for any other variables, i.e., using anything else than a measure of the short-term interest rate as an instrument. ${ }^{8}$

We order the short-term interest rate measure last and treat its innovations as monetary policy "shocks", in the standard way. This ordering imposes the identifying assumption that latent factors do not respond to monetary policy innovations within the quarter. To implement this identification scheme, as in Bernanke et al. (2005), we defined two categories of variables, namely, "slow-moving" and "fast-moving". Slow moving variables are those that do not respond contemporaneously to unanticipated monetary policy shocks. They include variables such as measures of output and production, consumption, employment, interest rates and prices. In contrast, fast moving variables respond contemporaneously to policy shocks. They mainly comprise of financial variables, such as asset-price, which, in turn is highly sensitive to contemporaneous economic shocks.

With the two-step estimation, the identification requires first controlling for the part of $C_{t}$ that corresponds to the monetary policy measure. To achieve this, first, the "slow-moving" factors, $F_{t}^{s}$, are estimated as the principal components of the "slow-moving" variables, and then, second, the following regression,

$$
\hat{C}_{t}=b_{F^{s}} \hat{F}_{t}^{s}+b_{Y} Y_{t}+e_{t}
$$

is estimated and $F_{t}^{n}$ obtained from $C_{t}^{n}-b_{Y} Y_{t}$. Note that since $F_{t}^{\wedge s}$ and $Y_{t}$ are correlated, so are $F_{t}^{n}$ and $Y_{t}$. Finally, the VAR in $F_{t}^{n}$ and $Y_{t}$, is estimated and identified recursively as discussed above.

The reduced-form VAR, based on Eq. (1), then has the following structural form:

$\Gamma(L)\left[\begin{array}{l}\hat{F}_{t} \\ Y_{t}\end{array}\right]=u_{t}$ 
where $\Gamma(L)$ is a conformable lag polynomial of finite order $p$ and $u_{t}$ is a vector of structural innovations. Given this, we compute the impulse response functions (IRFs) of $F_{t}^{n}$ and $Y_{t}$ as follows:

$$
\left[\begin{array}{l}
\hat{F}_{t} \\
Y_{t}
\end{array}\right]=\Psi(L) u_{t}
$$

where $\Psi(L)$ is a lag polynomial of order $h$ and $\Psi(L)=\Gamma(L)^{-1}$. Given that $X_{t}$ is estimated by $X_{t}^{\prime}=\Lambda^{f} F_{t}{ }^{\prime}+\Lambda^{y} Y_{t}^{\prime}+e_{t}^{\prime}$, based on Eq. (2), the IRFs of $X_{t}^{\prime}$ are given by:

$$
\hat{X}_{t}^{\prime}=\left[\hat{\Lambda}^{f} \hat{\Lambda}^{y}\right]\left[\begin{array}{c}
\hat{F}_{t}^{\prime} \\
Y_{t}^{\prime}
\end{array}\right]=\left[\begin{array}{ll}
\hat{\Lambda}^{f} & \hat{\Lambda}^{y}
\end{array}\right] \Psi(L) u_{t}^{\prime} \text {. }
$$

\section{Data}

Besides the real house price of the five segments of the housing market, the FAVAR is estimated based on 241 other quarterly series of South Africa, with the data covering the real, nominal, and financial sectors. We also have intangible variables, such as confidence indices, and survey data. The sample period contains data from 1980:01 to 2006:04. ${ }^{9}$ All series are seasonally adjusted and were made covariance stationary when estimating the DFM. The more powerful DF-GLS test, instead of the more popular ADF test, is used to assess the degree of integration of all series. All non-stationary series are made stationary through differencing. The Schwarz information criterion (SIC) is used in the selecting the appropriate lag length in such a way that no serial correction is left in the stochastic error term. Where there were doubts about the presence of unit root, the KPSS test, with the null hypothesis of stationarity, was applied.

There are various statistical approaches in determining the number of factors in the DFM. For example, Bai and $\mathrm{Ng}$ (2002) developed a set of criteria to guide the selection of the number of factors in large dimensional panels. The principal component analysis (PCA) can also be used in establishing the number of factors in the DFM. The PCA suggests that the selection of a number of factors $q$ be based on the first eigenvalues of the spectral density matrix of $X_{t}$. Then, the principal components are added until the increase in the explained variance is less than a specific $\alpha=0.05$. The Bai and $\mathrm{Ng}$ (2002) approach proposes five static factors, while Bai and Ng (2007) suggest two primitive or dynamic factors. Similar to the latter method, the principal component technique, as proposed by Forni et al. (2000) suggests two dynamic factors. The first two dynamic principal components explain approximately $99 \%$ of variation, while the eigenvalue of the third component being equal to $0.005<0.05$. So we use two dynamic factors in the estimation of a FAVAR with a lag length, $p$, equal to $4 .{ }^{10}$ Furthermore, we find that increasing the number of factors, reducing the lag length or breaking the sample period into smaller subsamples ${ }^{11}$ does not change the results substantially. To account for uncertainty in the estimation of the factors, a bootstrap technique based on Kilian (1998) is implemented. This is necessary in constructing the $90 \%$ confidence intervals of the impulse responses. 


\section{Empirical results}

Fig. 1 displays the impulse response functions of real house price growth rate of the five segments over 20 quarters, resulting from an increase in the $T B$. The $T B$ increases to approximately $0.25 \%$, and stays significant for a short period. Following the contractionary monetary policy, the impact on real house price growth rate across categories is negative in general. These results are in line with theory and we find no evidence of the so-called home price puzzle observed by Kasai and Gupta (2008). We attribute this difference to misspecification in small-scale VARs, due to their inability to take into account various potential predictors of house prices. The gain witnessed here suggests that a FAVAR methodology, which exploits a large set of information, improves the accuracy of econometric models in predicting the effects of monetary policy, and therefore, could address the puzzling effects observed otherwise. ${ }^{12}$
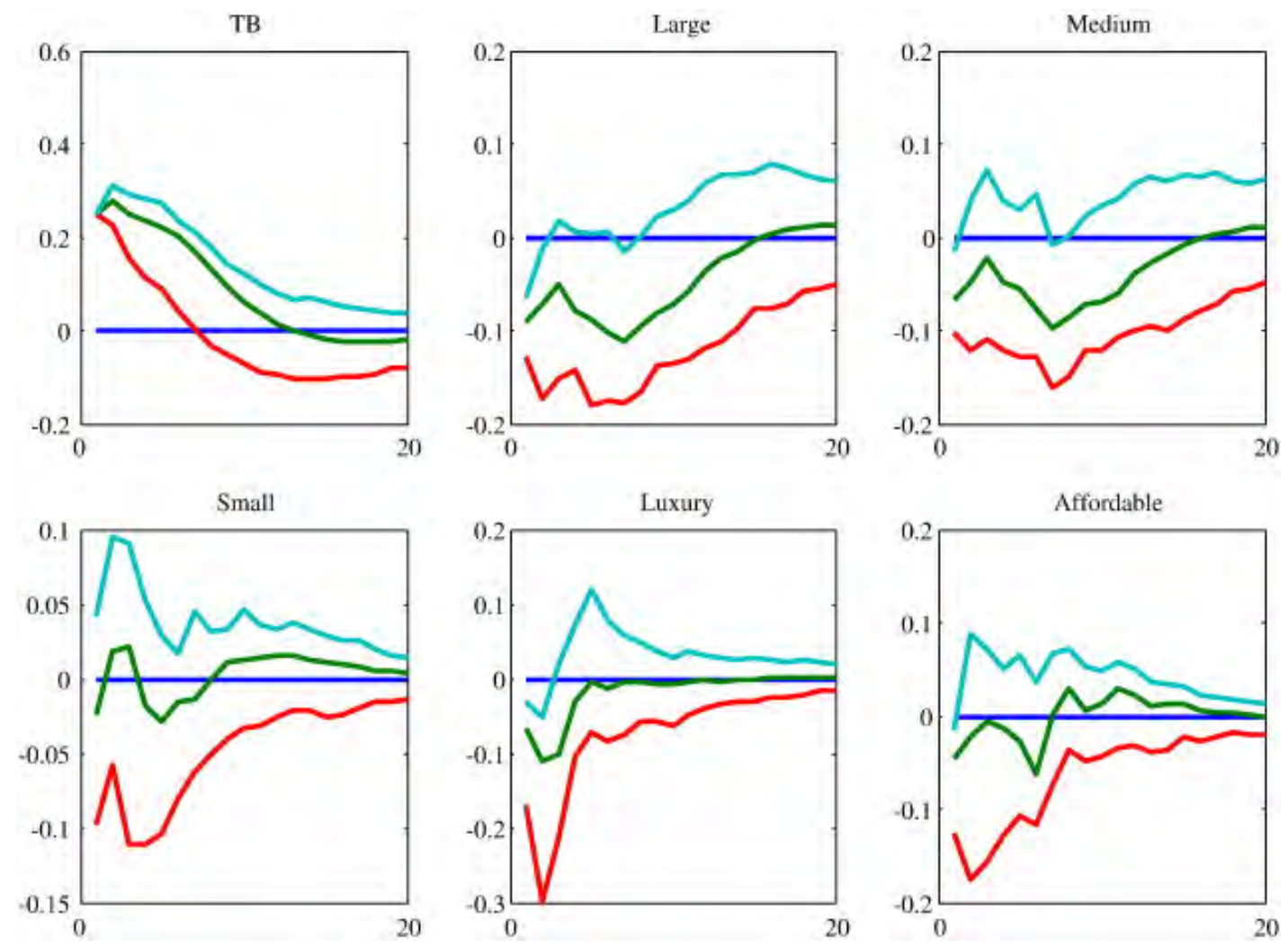

Fig. 1. IRFs of house price inflation following a monetary policy shock.

Note that the reaction of real house price growth rate to a contractionary monetary policy shock is different, especially with regards to the size and length of the impact, across the alternative housing categories, thereby vindicating the need to look at different segments of the housing market. Small-middle-segment and affordable housing display a small but negative effect at the impact. Following the increase in interest rate, real house price growth rate of small-middle and affordable-segments decreases by less than $0.05 \%$. However, for the small-middle-segment 
housing, the initial negative effect turns out to be insignificant and short lived. In the case of affordable houses, the early negative impact is significant but does not last long either.

Interestingly, for both these categories, the real house price growth rates start to fall again after the initial recovery and reaches negative levels that are similar in size to their initial impact. Further, for both these categories, the real house price growth rate becomes positive at around 8 quarters, and stays that way for the remainder of the period until the effect dies off. The drop in real house price growth for the large-middle-segment, the medium-middle-segment and luxury houses are significant, and lasts relatively longer than what is observed for the small-middlesegment and the affordable housing. Real house price growth rate of the large-middle- and medium-middle-segments plummet initially to approximately $0.1 \%$, and rise thereafter, and drop again sharply. They stay negative for about 15 quarters, before becoming positive and then die out progressively. For the luxury-category, the real house price growth rate displays a negative and significant response of approximately $0.07 \%$ at the impact, followed by another drop to $0.1 \%$ and then a sudden recovery that causes the effect to taper off after about 5 quarters.

At this juncture, some possible explanations about the behavior of the real house price growth rates of the five segments, following a contractionary monetary policy shock, is desired. Note, except for the luxury-segment, and irrespective of the size and significance of the impact, a common feature is observed amongst the four other categories of housing. We witness an initial decline of the real house price growth rate at the impact of the shock, followed by a recovery and then a decline again, before the effect starts to taper off. This we believe is possibly due to two reasons: First, this could indicate that house prices are slow moving variables, and second, and perhaps the more important of the two, the result is in line with Stock and Watson's (2003) suggestion that house prices lead to economic activity. Hence, the delayed effect could be because of the downturn in the economy, which in turn, originated from the decline in the housing sector. The second line of explanation is in line with Iacoviello and Neri (2008), who indicate significant spillovers from the housing market into the real economy, followed by economic activity affecting further the other sectors of the economy, including housing. This downturn could cause owners of the large-middle- and medium-middle-segment of the housing industry to start demanding more of small-middle-segment housing, causing the price of the latter to recover much quicker, while, the real house price growth rates of the other two larger middle-segment housing have to wait for a significant period of time. Besides, Gupta and Das (2008) indicate that for the small-middle-segment housing, what seems to be more important in the determination of its price is its past own price, and hence, the role of fundamentals is not too important. This is more so for affordable housing especially when one realizes that these are government provided and as such, have a controlled and rigid pricing structure. Finally, as far as the luxury-segment of the housing market is concerned, we observe an initial decline followed by a larger decline but a quick recovery. Given that the real house price growth rate falls further after the initial negative impact, seems to suggest the sluggishness of the market for this particular housing category, where the segment gets hit by the economic downturn before it could recover. The inherent lavish nature of the luxury housing, owned by people in the highest strata of income, as well as by foreigners, makes it a difficult market for quick transactions and movements of buyers and sellers. The resultant slow moving nature of house prices is, thus, quite logical. At the same time, luxury houses being bought mainly by the most affluent of the country with diverse portfolios, and by foreigners or South African citizens residing abroad, all of who are quite well-insured against the downturn, the fast recovery is not surprising. 
Other than impulse response functions, another exercise typically performed in the standard VAR context is variance decomposition, which determines, at a given horizon, the fraction of the forecasting error of a variable attributable to a particular shock. Formally, fraction variance of $Y_{t+k}-Y_{t+k}$ due to the monetary policy shock $\left(\varepsilon_{t}^{M S}\right)$ is expressed as follows:

$$
\frac{\operatorname{var}\left(Y_{t+k}-\hat{Y}_{t+k / t} \mid \varepsilon_{t}^{M S}\right)}{\operatorname{var}\left(Y_{t+k}-\hat{Y}_{t+k \mid t}\right)}
$$

Note, as indicated by Eq. (2), part of the variance of the macroeconomic variables comes from their idiosyncratic component, which in part might be capturing measurement error and should not be affected by business cycle determinants. Given this, the variance decomposition of the FAVAR framework measures the relative importance of a structural shock only to the portion of the variable explained by the common factors. More precisely, this variance decomposition for $X_{i t}$ can be expressed as:

$$
\frac{\Lambda_{i} \operatorname{var}\left(C_{t+K}-\hat{C}_{t+K \mid t} \mid \varepsilon_{t}^{M S}\right) \Lambda_{i}^{\prime}}{\Lambda_{i} \operatorname{var}\left(C_{t+K}-\hat{C}_{t+K \mid t}\right) \Lambda_{i}^{\prime}}
$$

where $\Lambda_{i}$ denotes the ith line of $\Lambda=\left[\Lambda^{f}, \Lambda^{y}\right]$ and $\operatorname{var}\left(C_{t}+K^{-} \hat{C}_{t+K \mid t} \mid \varepsilon_{t}^{M S}\right) / \operatorname{var}\left(C_{t}+K^{-} \hat{C}_{t+k \mid t}\right)$ is the standard VAR variance decomposition based on Eq. (1).

Table 1 reports the variance decomposition results for real house price growth rate in the five categories of the South African housing market analyzed in Fig. 1. The first column reports the contribution of the monetary policy shock to the variance of the forecast of the common component, at the 20 quarter horizon, while, the second column contains the $R^{2}$ of the common component for each of these variables. The product of the two columns is the equivalent of the variance decomposition that would be obtained from a standard VAR. The results suggest small effect of monetary policy on real house price growth, with the same explaining between $0.39 \%$ (Affordable) to $4.88 \%$ (Luxury) of the variation. Looking at the $R^{2}$ of the common component, we can make the following observations: First, the factors explain a sizeable fraction of these variables, especially for the large- and medium-middle-segments and affordable housing. This confirms that the FAVAR framework does capture important dimensions of the business cycle movements, at least for three categories of the South African housing market. Second, given the $R^{2}$ of the common components, the discrepancies in the variance decomposition between the standard VAR and that of the FAVAR are quite considerable. Finally, the differences in the sizes of variance decomposition is also indicative of the inherent structural heterogeneity within these five categories, but more importantly, their sizes tend to match the (initial) impact of the monetary policy shock on the real house price growth rates of the different categories. 
Table 1.

Variance decomposition of real house price growth in five categories of the South African housing market.

\begin{tabular}{|l|l|l|}
\hline Categories & Variance decomposition & $\boldsymbol{R}^{\mathbf{2}}$ \\
\hline Large-middle-segment & 0.0192 & 0.6679 \\
\hline Medium-middle-segment & 0.0092 & 0.5897 \\
\hline Small-middle-segment & 0.0045 & 0.1022 \\
\hline Luxury & 0.0488 & 0.1147 \\
\hline Affordable & 0.0039 & 0.3653 \\
\hline
\end{tabular}

Notes: The column entitled "Variance decomposition" reports the fraction of the variance of the forecast error of the common component, at the 20-quarter horizon, explained by the monetary policy shock. " $R$ ", refers to the fraction of the variance of the variable explained by the common factors, $\left(F_{t}^{n}, Y_{t}\right)$.

\section{Conclusions}

This paper assesses the impact of a positive monetary policy shock on real house price growth for the five segments of the South African economy using a FAVAR estimated with 246 variables spanning the period of 1980:Q1 to 2006:Q4. Overall, the results show that real house price growth responds negatively to a positive monetary policy shock, suggesting that the framework does not experience the home price puzzle, encountered by Kasai and Gupta (2008) while analyzing monetary policy shocks with three-variable SVARs for the middle-segment of the South African housing market. This result points to the benefit gained by using a large information set. Not surprisingly, the reaction of real house price growth rate is found to differ across the five housing categories, indicating the segmented nature of the market. Specifically, we find the luxury, the large-middle- and the medium-middle-segments to experience the biggest negative impacts following a contractionary monetary policy. However, unlike the two middlesegments, the effect on luxury housing recovers back to its original level much faster. The lower end of the market, i.e., the small-middle-segment and affordable housing witness small and short-lived negative effects.

As part of future research, it would be interesting to analyze the robustness of the results based on a large-scale Bayesian VAR (LBVAR), developed recently by Banbura et al. (2008), since just like the FAVAR, the LBVAR, given its estimation methodology, can also handle a data set of any size. Moreover, unlike the FAVAR, the LBVAR, via appropriate design of the interaction matrix of the variables, can account for spatial influences of neighboring regions and also asymmetric effects of regional variables and national variables on each other. Note, regional 
variables are likely to have minor effects on national variables, while, the national variables are more prone to affect the regional variables strongly. However, given that regional (provincial) level house price data in South Africa is only limited to the middle-segment, we would have to restrict our analysis to this section of the housing market only. Nevertheless, a regional analysis would be worth the endeavor in understanding which province(s) in South Africa plays an important role in determining the dynamics of the national house price. Finally, given that the Bayesian methodology does not require us to ensure stationarity of variables, we can analyze house prices at levels rather than their growth rates, if necessary.

\section{Appendix A. Macroeconomic series}

\begin{tabular}{|c|c|c|c|}
\hline Number & Variable name & Log & Stationarity \\
\hline \multicolumn{4}{|c|}{ Interest rates } \\
\hline 1 & Treasury Bill rate & $\mathrm{nl}$ & 0 \\
\hline 2 & Money market rate & $\mathrm{nl}$ & 0 \\
\hline 3 & Deposit rate & $\mathrm{nl}$ & 0 \\
\hline 4 & Lending rate & $\mathrm{nl}$ & 0 \\
\hline 5 & Discount rate & $\mathrm{nl}$ & 0 \\
\hline 6 & Government bond yield & $\mathrm{nl}$ & 0 \\
\hline \multicolumn{4}{|c|}{ House prices } \\
\hline 7 & House price growth large & $\mathrm{nl}$ & 0 \\
\hline 8 & House price growth medium & $\mathrm{nl}$ & 0 \\
\hline 9 & House price growth small & $\mathrm{nl}$ & 0 \\
\hline 10 & House price growth luxury & $\mathrm{nl}$ & 0 \\
\hline 11 & House price growth affordable & $\mathrm{nl}$ & 0 \\
\hline \multicolumn{4}{|c|}{ Stock prices } \\
\hline 12 & All share industrials & 1 & 1 \\
\hline 13 & Banks & 1 & 1 \\
\hline 14 & Financials & 1 & 1 \\
\hline 15 & Industrials and financials & 1 & 1 \\
\hline
\end{tabular}




\begin{tabular}{|c|c|c|c|}
\hline Number & Variable name & $\log$ & Stationarity \\
\hline 16 & Property unit trust & 1 & 1 \\
\hline 17 & Resources & 1 & 1 \\
\hline \multicolumn{4}{|c|}{ Confidence BER } \\
\hline 18 & Business confidence index - RMB/BER & 1 & 1 \\
\hline 19 & Coincidence indicator & 1 & 1 \\
\hline 20 & Lagging indicator & 1 & 0 \\
\hline 21 & Leading indicator & 1 & 1 \\
\hline \multicolumn{4}{|c|}{ Exchange rates } \\
\hline 22 & Rand/dollar & 1 & 1 \\
\hline 23 & Rand/euro & 1 & 1 \\
\hline 24 & Rand/pounds & 1 & 1 \\
\hline 25 & Exchange rate index $2000=100$ & 1 & 1 \\
\hline 26 & NNEER from INS (index ) & 1 & 1 \\
\hline 27 & REER (index) & 1 & 1 \\
\hline \multicolumn{4}{|l|}{ Velocity } \\
\hline 28 & Income velocity of circulation of money: V1(A) & 1 & 1 \\
\hline 29 & Income velocity of circulation of money: V1 & 1 & 1 \\
\hline 30 & Income velocity of circulation of money: V2 & 1 & 1 \\
\hline 31 & Income velocity of circulation of money: V3 & 1 & 1 \\
\hline \multicolumn{4}{|c|}{ Monetary aggregates } \\
\hline 32 & Narrow money (M1) sa - units: $2000=100$ & 1 & 1 \\
\hline 33 & Monetary aggregate (M1) sa & 1 & 1 \\
\hline 34 & Monetary aggregate (M3) sa & 1 & 1 \\
\hline 35 & Monetary aggregate (M2) sa & 1 & 1 \\
\hline
\end{tabular}




\begin{tabular}{|c|c|c|c|}
\hline Number & Variable name & Log & Stationarity \\
\hline \multicolumn{4}{|c|}{ Credit to private sector } \\
\hline 36 & $\begin{array}{l}\text { Monetary sector assets: total credit extended to the private sector } 12- \\
\text { term \% change }\end{array}$ & $\mathrm{nl}$ & 0 \\
\hline 37 & $\begin{array}{l}\text { Monetary sector assets: total credit extended to the private sector } \\
\text { change over } 1 \text { term }\end{array}$ & $\mathrm{nl}$ & 0 \\
\hline 38 & Monetary sector assets: total credit extended to the private sector & 1 & 1 \\
\hline \multicolumn{4}{|c|}{ Credit to private sector } \\
\hline 39 & GDP deflator & 1 & 1 \\
\hline 40 & Consumer prices: total — \% change (period) & $\mathrm{nl}$ & 0 \\
\hline \multicolumn{4}{|c|}{ National account } \\
\hline 41 & Gross domestic product at market prices -2000 prices & 1 & 1 \\
\hline 42 & Final consumption expenditure by households — 2000 prices & 1 & 1 \\
\hline 43 & $\begin{array}{l}\text { Final consumption expenditure by general government — } 2000 \\
\text { prices }\end{array}$ & 1 & 1 \\
\hline 44 & $\begin{array}{l}\text { Gross capital formation: gross fixed capital formation }-2000 \\
\text { prices }\end{array}$ & 1 & 1 \\
\hline 45 & Gross capital formation: change in inventories - 2000 prices & $\mathrm{nl}$ & 0 \\
\hline 46 & Residual item — 2000 prices & $\mathrm{nl}$ & 0 \\
\hline 47 & Gross domestic expenditure — 2000 prices & 1 & 0 \\
\hline 48 & Exports of goods and services — 2000 prices & 1 & 1 \\
\hline 49 & Imports of goods and services — 2000 prices & 1 & 1 \\
\hline \multicolumn{4}{|c|}{ Value added } \\
\hline 50 & GDP: primary sector — constant 2000 prices & 1 & 0 \\
\hline 51 & $\begin{array}{l}\text { GDP: primary sector — agriculture, forestry and fishing — constant } \\
2000 \text { prices }\end{array}$ & 1 & 0 \\
\hline 52 & $\begin{array}{l}\text { GDP: primary sector — mining and quarrying — constant } 2000 \\
\text { prices }\end{array}$ & 1 & 1 \\
\hline 53 & GDP: secondary sector — constant 2000 prices & 1 & 1 \\
\hline
\end{tabular}




\begin{tabular}{|c|c|c|c|}
\hline Number & Variable name & Log & Stationarity \\
\hline 54 & GDP: secondary sector — manufacturing — constant 2000 prices & 1 & 1 \\
\hline 55 & $\begin{array}{l}\text { GDP: secondary sector — electricity, gas and water — constant } \\
2000 \text { prices }\end{array}$ & 1 & 1 \\
\hline 56 & $\begin{array}{l}\text { GDP: secondary sector — construction (contractors) — constant } \\
2000 \text { prices }\end{array}$ & 1 & 1 \\
\hline 57 & GDP: tertiary sector — constant 2000 prices & 1 & 1 \\
\hline 58 & $\begin{array}{l}\text { GDP: tertiary sector — wholesale and retail trade, catering and } \\
\text { accommodationrices }\end{array}$ & 1 & 1 \\
\hline 59 & GDP: tertiary sector — transport, storage and communication & 1 & 1 \\
\hline 60 & $\begin{array}{l}\text { GDP: tertiary sector — financial intermediation, insurance, real } \\
\text { estate and business services }\end{array}$ & 1 & 1 \\
\hline 61 & $\begin{array}{l}\text { GDP: tertiary sector — community, social and personal services - } \\
\text { constant } 2000 \text { prices }\end{array}$ & 1 & 1 \\
\hline 62 & $\begin{array}{l}\text { GDP: tertiary sector — community, social and personal services - } \\
\text { general government servicesices }\end{array}$ & 1 & 1 \\
\hline 63 & $\begin{array}{l}\text { GDP: tertiary sector — community, social and personal services - } \\
\text { other services es }\end{array}$ & 1 & 1 \\
\hline 64 & Gross value added at basic prices — constant 2000 prices & 1 & 1 \\
\hline 65 & Balance of payments: value of merchandise exports & l & 1 \\
\hline 66 & Balance of payments: value of merchandise exports & nl & 0 \\
\hline 67 & Balance of payments: value of net gold exports & 1 & 0 \\
\hline 68 & Balance of payments: value of net gold exports 1-term \% change & $\mathrm{nl}$ & 0 \\
\hline 69 & Balance of payments: value of merchandise imports & 1 & 0 \\
\hline 70 & $\begin{array}{l}\text { Balance of payments: value of merchandise imports, f.o.b 1-term \% } \\
\text { change }\end{array}$ & $\mathrm{nl}$ & 0 \\
\hline 71 & Value of payments for services & l & 0 \\
\hline 72 & Value of payments for services 1-term \% change & $\mathrm{nl}$ & 0 \\
\hline 73 & $\begin{array}{l}\text { Ratio of balance on current account to gross domestic product at } \\
\text { current prices (percentage), }\end{array}$ & $\mathrm{nl}$ & 0 \\
\hline 74 & Ratio of real merchandise exports to gross domestic product & $\mathrm{nl}$ & 0 \\
\hline
\end{tabular}




\begin{tabular}{|c|c|c|c|}
\hline Number & Variable name & Log & Stationarity \\
\hline 75 & $\begin{array}{l}\text { Ratio of real merchandise imports to gross domestic expenditure } \\
\text { (percentage) }\end{array}$ & $\mathrm{nl}$ & 0 \\
\hline \multicolumn{4}{|c|}{ Utilisation of production capacity } \\
\hline 76 & Percentage utilisation of production capacity: durable goods & $\mathrm{nl}$ & 0 \\
\hline 77 & Percentage utilisation of production capacity: non-durable goods & $\mathrm{nl}$ & 0 \\
\hline 78 & Percentage utilisation of production capacity: total & $\mathrm{nl}$ & 0 \\
\hline 79 & Labour productivity - index $2000=100$ & 1 & 1 \\
\hline 80 & Nominal unit labour costs - index $2000=100$ & l & 1 \\
\hline \multicolumn{4}{|c|}{ Industrial production } \\
\hline 81 & Industrial production: manufacturing sa — units: $2000 \mathrm{Y}$ & l & 1 \\
\hline 82 & Manufacturing — orders inflow/demand: tendency & $\mathrm{nl}$ & 0 \\
\hline 83 & Manufacturing — orders inflow/demand: tendency & $\mathrm{nl}$ & 0 \\
\hline \multicolumn{4}{|c|}{ Industrial production } \\
\hline 84 & Production in total mining — units: $2000=100$ & 1 & 0 \\
\hline 85 & Production of gold — units: $2000=100$ & 1 & 1 \\
\hline 86 & Production in total mining sa — units: $2000=100$ & 1 & 0 \\
\hline 87 & Production of manufactured crude steel & 1 & 0 \\
\hline \multicolumn{4}{|c|}{ International trade } \\
\hline 88 & Exports: excluding gold - volume $-2000=100$ & 1 & 1 \\
\hline 89 & Exports: excluding gold - price $-2000=100$ & 1 & 1 \\
\hline 90 & Exports: including gold - volume $-2000=100$ & l & 1 \\
\hline 91 & Exports: including gold - price $-2000=100$ & 1 & 1 \\
\hline 92 & Imports: volume $-2000=100$ & 1 & 1 \\
\hline 93 & Imports: price $-2000=100$ & 1 & 1 \\
\hline 94 & Terms of trade: excluding gold $-2000=100$ & 1 & 1 \\
\hline
\end{tabular}




\begin{tabular}{|c|c|c|c|}
\hline Number & Variable name & Log & Stationarity \\
\hline 95 & Terms of trade: including gold $-2000=100$ & l & 1 \\
\hline \multicolumn{4}{|l|}{ Mining } \\
\hline 96 & Mining production: total, gold included — index $2000=100$ & 1 & 1 \\
\hline 97 & Mining production: total, gold excluded - index $2000=100$ & 1 & 1 \\
\hline 98 & Mining production: gold - index $2000=100$ & 1 & 1 \\
\hline 99 & Mining production: iron ore - index $2000=100$ & 1 & 1 \\
\hline 100 & Mining production: chrome - index $2000=100$ & 1 & 0 \\
\hline 101 & Mining production: copper — index $2000=100$ & 1 & 1 \\
\hline 102 & Mining production: manganese ore — index $2000=100$ & l & 0 \\
\hline 103 & Mining production: platinum group metals — index $2000=100$ & l & 1 \\
\hline 104 & Mining production: nickel — index $2000=100$ & l & 1 \\
\hline 105 & Mining production: other metallic minerals — index 2000 = 100 & l & 1 \\
\hline 106 & Mining production: diamonds — index $2000=100$ & l & 1 \\
\hline 107 & Mining production: coal $—$ index $2000=100$ & 1 & 1 \\
\hline 108 & Mining production: building materials — index $2000=100$ & 1 & 1 \\
\hline 109 & $\begin{array}{l}\text { Mining production: other non-metallic minerals — index } \\
2000=100\end{array}$ & l & 1 \\
\hline \multicolumn{4}{|c|}{ Manufacturing production } \\
\hline 110 & Gross fixed capital formation: manufacturing constant 2000 prices & 1 & 1 \\
\hline 111 & $\begin{array}{l}\text { Gross value added at basic prices of manufacturing constant } 2000 \\
\text { prices }\end{array}$ & l & 1 \\
\hline 112 & Taxes on production and imports current prices & l & 1 \\
\hline 113 & Employment in the private sector: manufacturing index $2000=100$ & l & 1 \\
\hline 114 & $\begin{array}{l}\text { Production prices of goods for domestic use produced in SA: total } \\
\text { manufacturing }\end{array}$ & $\mathrm{nl}$ & 0 \\
\hline 115 & Production prices of goods for domestic use produced in SA: total & $\mathrm{nl}$ & 0 \\
\hline
\end{tabular}




\begin{tabular}{|c|c|c|c|}
\hline Number & Variable name & Log & Stationarity \\
\hline 116 & Production prices of imported goods for domestic & $\mathrm{nl}$ & 0 \\
\hline 117 & Total production prices of goods for domestic & $\mathrm{nl}$ & 0 \\
\hline 118 & Production prices of farming requisites index $2000=100$ & 1 & 1 \\
\hline 119 & $\begin{array}{l}\text { Manufacturing: percentage utilisation of production capacity of } \\
\text { durable goods }\end{array}$ & $\mathrm{nl}$ & 0 \\
\hline \multicolumn{4}{|l|}{ Car sales } \\
\hline 120 & Retail car sales incl AMH & 1 & 1 \\
\hline 121 & Total car \& commercial vehicle sales incl AMH & 1 & 1 \\
\hline \multicolumn{4}{|l|}{ Labour } \\
\hline 122 & Labour productivity in the non-agricultural sectors index $2000=100$ & 1 & 1 \\
\hline 123 & Labour productivity in the non-agricultural sectors 4-term \% change & $\mathrm{nl}$ & 0 \\
\hline 124 & Unit labour costs in the non-agricultural sectors index $2000=100$ & 1 & 1 \\
\hline 125 & Unit labour costs in the non-agricultural sectors 4-term \% change & $\mathrm{nl}$ & 0 \\
\hline 126 & Manufacturing: labour productivity index $2000=100$ & 1 & 1 \\
\hline 127 & Manufacturing: unit labour costs index $2000=100$ & l & 1 \\
\hline 128 & $\begin{array}{l}\text { Employment by public authorities: general government index } \\
2000=100\end{array}$ & 1 & 1 \\
\hline 129 & $\begin{array}{l}\text { Employment by public authorities: business enterprises index } \\
2000=100\end{array}$ & 1 & 1 \\
\hline \multicolumn{4}{|l|}{ Labour } \\
\hline 130 & Total employment by public authorities index $2000=100$ & 1 & 1 \\
\hline 131 & Total employment by public authorities & $\mathrm{nl}$ & 0 \\
\hline 132 & Employment in the private sector: mining index $2000=100$ & l & 1 \\
\hline 133 & Employment in the private sector: manufacturing index $2000=100$ & 1 & 1 \\
\hline 134 & Employment in the private sector: construction index $2000=100$ & 1 & 1 \\
\hline 135 & Employment in the private sector: trade index $2000=100$ & l & 1 \\
\hline
\end{tabular}




\begin{tabular}{|c|c|c|c|}
\hline Number & Variable name & Log & Stationarity \\
\hline 136 & $\begin{array}{l}\text { Employment in the private sector: financial intermediation and } \\
\text { insurance index } 2000=100\end{array}$ & l & 1 \\
\hline 137 & Total employment in the private sector index $2000=100$ & l & 1 \\
\hline 138 & $\begin{array}{l}\text { Total employment in the private sector seasonally adjusted at annual } \\
\text { rate }\end{array}$ & $\mathrm{nl}$ & 0 \\
\hline 139 & Total employment in the non-agricultural sectors index $2000=100$ & 1 & 1 \\
\hline 140 & Total employment in the non-agricultural sectors seasonally adjusted & $\mathrm{nl}$ & 0 \\
\hline \multicolumn{4}{|l|}{ Prices } \\
\hline 141 & $\begin{array}{l}\text { Prices of exports: goods and non-factor services, f.o.b excluding } \\
\text { gold index } 2000=100\end{array}$ & 1 & 1 \\
\hline 142 & Prices of imports: goods and non-factor services Index $2000=100$ & l & 1 \\
\hline 143 & Prices of net gold exports 1-term \% change & $\mathrm{nl}$ & 0 \\
\hline 144 & Prices of merchandise exports, f.o.b 1-term \% change & $\mathrm{nl}$ & 0 \\
\hline 145 & Prices of merchandise imports, f.o.b 1-term \% change & $\mathrm{nl}$ & 0 \\
\hline \multicolumn{4}{|l|}{$P P I$} \\
\hline 146 & PPI: all groups — index $2000=100$ & 1 & 1 \\
\hline 147 & PPI: all groups: South African — index $2000=100$ & 1 & 1 \\
\hline 148 & PPI: all groups: imported — index $2000=100$ & 1 & 1 \\
\hline 149 & PPI: agriculture, forestry, fishing \& mining — index $2000=100$ & 1 & 1 \\
\hline 150 & $\begin{array}{l}\text { PPI: agriculture, forestry, fishing \& mining: agriculture — index } \\
2000=100\end{array}$ & 1 & 1 \\
\hline 151 & $\begin{array}{l}\text { PPI: agriculture, forestry, fishing \& mining: agriculture — food — } \\
\text { index } 2000=100\end{array}$ & l & 1 \\
\hline 152 & $\begin{array}{l}\text { PPI: agriculture, forestry, fishing \& mining: agriculture — other } \\
\text { agriculture — index } 2000=100\end{array}$ & l & 1 \\
\hline 153 & $\begin{array}{l}\text { PPI: agriculture, forestry, fishing \& mining: forestry — index } \\
2000=100\end{array}$ & l & 1 \\
\hline 154 & PPI: agriculture, forestry, fishing \& mining: fishing — index & 1 & 1 \\
\hline
\end{tabular}




\begin{tabular}{|c|c|c|c|}
\hline Number & Variable name & Log & Stationarity \\
\hline & $2000=100$ & & \\
\hline 155 & $\begin{array}{l}\text { PPI: agriculture, forestry, fishing \& mining: mining \& quarrying — } \\
\text { index } 2000=100\end{array}$ & l & 1 \\
\hline 156 & $\begin{array}{l}\text { PPI: agriculture, forestry, fishing \& mining: mining \& quarrying — } \\
\text { coal — index } 2000=100\end{array}$ & 1 & 1 \\
\hline 157 & PPI: manufacturing - index $2000=100$ & 1 & 1 \\
\hline 158 & PPI: manufacturing: South African — index $2000=100$ & 1 & 1 \\
\hline 159 & PPI: manufacturing: imported — index $2000=100$ & 1 & 1 \\
\hline 160 & PPI: manufacturing: food — index $2000=100$ & 1 & 1 \\
\hline 161 & $\begin{array}{l}\text { PPI: manufacturing: food — meat — fresh meat — index } \\
2000=100\end{array}$ & l & 1 \\
\hline 162 & PPI: manufacturing: beverages — index $2000=100$ & 1 & 1 \\
\hline 163 & PPI: manufacturing: tobacco products - index $2000=100$ & 1 & 1 \\
\hline 164 & PPI: manufacturing: textiles \& made-up goods — index $2000=100$ & 1 & 1 \\
\hline 165 & PPI: manufacturing: wearing apparel - index $2000=100$ & 1 & 1 \\
\hline 166 & PPI: manufacturing: leather \& leather products — index $2000=100$ & 1 & 1 \\
\hline 167 & PPI: manufacturing: footwear — index $2000=100$ & 1 & 1 \\
\hline 168 & PPI: manufacturing: wood \& wood products - index $2000=100$ & 1 & 1 \\
\hline 169 & $\begin{array}{l}\text { PPI: manufacturing: paper, paper products \& printing — index } \\
2000=100\end{array}$ & 1 & 1 \\
\hline 170 & $\begin{array}{l}\text { PPI: manufacturing: products of petroleum \& coal — index } \\
2000=100\end{array}$ & 1 & 1 \\
\hline 171 & $\begin{array}{l}\text { PPI: manufacturing: chemicals \& chemical products — index } \\
2000=100\end{array}$ & 1 & 1 \\
\hline \multicolumn{4}{|l|}{$P P I$} \\
\hline 172 & PPI: manufacturing: rubber \& plastic products - index $2000=100$ & 1 & 1 \\
\hline 173 & $\begin{array}{l}\text { PPI: manufacturing: non-metallic mineral products — index } \\
2000=100\end{array}$ & 1 & 1 \\
\hline 174 & PPI: manufacturing: basic metals - index $2000=100$ & 1 & 1 \\
\hline
\end{tabular}




\begin{tabular}{|c|c|c|c|}
\hline Number & Variable name & Log & Stationarity \\
\hline 175 & PPI: manufacturing: basic metals - ferrous - index $2000=100$ & 1 & 1 \\
\hline 176 & $\begin{array}{l}\text { PPI: manufacturing: basic metals — non-ferrous — index } \\
2000=100\end{array}$ & 1 & 1 \\
\hline 177 & PPI: manufacturing: metal products - index $2000=100$ & 1 & 1 \\
\hline 178 & $\begin{array}{l}\text { PPI: manufacturing: non-electrical machinery \& equipment — index } \\
2000=100\end{array}$ & 1 & 1 \\
\hline 179 & $\begin{array}{l}\text { PPI: manufacturing: electrical machinery \& apparatus — index } \\
2000=100\end{array}$ & 1 & 1 \\
\hline 180 & $\begin{array}{l}\text { PPI: manufacturing: medical, precision \& optical instruments - } \\
\text { index } 2000=100\end{array}$ & 1 & 1 \\
\hline 181 & PPI: manufacturing: transport equipment - index $2000=100$ & l & 1 \\
\hline 182 & PPI: manufacturing: furniture — index $2000=100$ & 1 & 1 \\
\hline 183 & PPI: electricity, gas, steam \& water - index $2000=100$ & 1 & 1 \\
\hline 184 & $\begin{array}{l}\text { Production prices: South African goods — manufacturing — \% } \\
\text { change }\end{array}$ & $\mathrm{nl}$ & 0 \\
\hline 185 & Production prices: South African goods — total — \% change & $\mathrm{nl}$ & 0 \\
\hline 186 & Production prices: imported goods — \% change & $\mathrm{nl}$ & 0 \\
\hline 187 & Production prices: South African goods — total — \% change & $\mathrm{nl}$ & 0 \\
\hline \multicolumn{4}{|l|}{$C P I$} \\
\hline 188 & CPI: all items — index $2000=100$ & 1 & 1 \\
\hline 189 & CPI: commodities — index $2000=100$ & l & 1 \\
\hline 190 & CPI: services - index $2000=100$ & 1 & 1 \\
\hline 191 & CPI: all items, excluding housing — index $2000=100$ & 1 & 1 \\
\hline 192 & CPI: all items, excluding food — index $2000=100$ & l & 1 \\
\hline 193 & CPI: food — index $2000=100$ & l & 1 \\
\hline 194 & $\begin{array}{l}\text { CPI: food excluding coffee, tea and cocoa: grain products — index } \\
2000=100\end{array}$ & 1 & 1 \\
\hline 195 & CPI: food excluding coffee, tea and cocoa: meat — index & 1 & 1 \\
\hline
\end{tabular}




\begin{tabular}{|c|c|c|c|}
\hline Number & Variable name & Log & Stationarity \\
\hline & $2000=100$ & & \\
\hline 196 & $\begin{array}{l}\text { CPI: food excluding coffee, tea and cocoa: fish and other seafood - } \\
\text { index } 2000=100\end{array}$ & 1 & 1 \\
\hline 197 & $\begin{array}{l}\text { CPI: food excluding coffee, tea and cocoa: milk, cheese and eggs - } \\
\text { index } 2000=100\end{array}$ & 1 & 1 \\
\hline 198 & CPI: food - fats and oils - index $2000=100$ & 1 & 1 \\
\hline 199 & $\begin{array}{l}\text { CPI: food excluding coffee, tea and cocoa: fruit and nuts — index } \\
2000=100\end{array}$ & l & 1 \\
\hline 200 & $\begin{array}{l}\text { CPI: food excluding coffee, tea and cocoa: vegetables — index } \\
2000=100\end{array}$ & 1 & 1 \\
\hline 201 & $\begin{array}{l}\text { CPI: food excluding coffee, tea and cocoa: sugar — index } \\
2000=100\end{array}$ & l & 1 \\
\hline 202 & CPI: beverages: coffee, tea and cocoa - index $2000=100$ & 1 & 1 \\
\hline 203 & $\begin{array}{l}\text { CPI: food excluding coffee, tea and cocoa: other — index } \\
2000=100\end{array}$ & l & 1 \\
\hline 204 & CPI: non-alcoholic beverages $—$ index $2000=100$ & l & 1 \\
\hline 205 & CPI: alcoholic beverages — index $2000=100$ & l & 1 \\
\hline 206 & CPI: cigarettes ,cigars and tobacco — index $2000=100$ & 1 & 1 \\
\hline 207 & CPI: clothing and footwear — index $2000=100$ & 1 & 1 \\
\hline 208 & CPI: clothing and footwear: clothing — index $2000=100$ & 1 & 1 \\
\hline 209 & CPI: clothing and footwear: footwear — index $2000=100$ & 1 & 1 \\
\hline 210 & CPI: housing — index $2000=100$ & l & 1 \\
\hline 211 & CPI: fuel and power - index $2000=100$ & 1 & 1 \\
\hline 212 & CPI: furniture and equipment — index $2000=100$ & 1 & 1 \\
\hline 213 & CPI: furniture and equipment: furniture — index 2000 = 100 & 1 & 1 \\
\hline 214 & CPI: furniture and equipment: appliances — index $2000=100$ & 1 & 1 \\
\hline 215 & $\begin{array}{l}\text { CPI: furniture and equipment: other household equipment and } \\
\text { textiles }- \text { index } 2000=100\end{array}$ & 1 & 1 \\
\hline 216 & CPI: household operation $—$ index $2000=100$ & 1 & 1 \\
\hline
\end{tabular}




\begin{tabular}{|c|c|c|c|}
\hline Number & Variable name & Log & Stationarity \\
\hline 217 & $\begin{array}{l}\text { CPI: household operation: household consumables — index } \\
2000=100\end{array}$ & 1 & 1 \\
\hline 218 & CPI: household operation: domestic workers — index $2000=100$ & 1 & 1 \\
\hline 219 & $\begin{array}{l}\text { CPI: household operation: other household services — index } \\
2000=100\end{array}$ & 1 & 1 \\
\hline \multicolumn{4}{|l|}{$C P I$} \\
\hline 220 & CPI: health — index $2000=100$ & 1 & 1 \\
\hline 221 & CPI: transport - index $2000=100$ & 1 & 1 \\
\hline 222 & CPI: transport: vehicles — index $2000=100$ & l & 1 \\
\hline 223 & CPI: transport: running cost - index $2000=100$ & l & 1 \\
\hline 224 & CPI: transport: public and hired transport - index $2000=100$ & 1 & 1 \\
\hline 225 & $\begin{array}{l}\text { CPI: miscellaneous goods and services: communication — index } \\
2000=100\end{array}$ & 1 & 1 \\
\hline 226 & $\begin{array}{l}\text { CPI: leisure entertaiment and culture: recreation and entertainment } \\
\text { - index } 2000=100\end{array}$ & l & 1 \\
\hline 227 & $\begin{array}{l}\text { CPI: leisure entertaiment and culture: reading matter — index } \\
2000=100\end{array}$ & l & 1 \\
\hline 228 & CPI: education — index $2000=100$ & l & 1 \\
\hline 229 & $\begin{array}{l}\text { CPI: miscellaneous goods and services: personal care — index } \\
2000=100\end{array}$ & l & 1 \\
\hline 230 & CPI: miscellaneous goods and services: other - index $2000=100$ & 1 & 1 \\
\hline 231 & Consumer prices: services — housing — \% change & $\mathrm{nl}$ & 0 \\
\hline 232 & Consumer prices: services — total — \% change & $\mathrm{nl}$ & 0 \\
\hline 233 & Consumer prices: goods: food — \% change & $\mathrm{nl}$ & 0 \\
\hline 234 & Consumer prices: goods: total — \% change nl & & \\
\hline \multicolumn{4}{|c|}{ Renumeration per worker } \\
\hline 235 & $\begin{array}{l}\text { Remuneration per worker in non-agriculture: public sector constant } \\
2000 \text { prices. Index } 2000=100\end{array}$ & 1 & 1 \\
\hline
\end{tabular}




\begin{tabular}{|l|l|l|l|}
\hline Number & Variable name & Log & Stationarity \\
\hline 236 & $\begin{array}{l}\text { Remuneration per worker in non-agriculture: public sector index } \\
2000=100\end{array}$ & 1 & 1 \\
\hline 237 & $\begin{array}{l}\text { Remuneration per worker in non-agriculture: public sector 4-term \% } \\
\text { change }\end{array}$ & $\mathrm{nl}$ & 0 \\
\hline 238 & $\begin{array}{l}\text { Remuneration per worker in non-agriculture: public sector 4-term \% } \\
\text { change at constant prices }\end{array}$ & $\mathrm{nl}$ & 0 \\
\hline 239 & $\begin{array}{l}\text { Remuneration per worker in the private sector constant 2000 prices. } \\
\text { Index } 2000=100\end{array}$ & $\mathrm{l}$ & 1 \\
\hline 240 & $\begin{array}{l}\text { Remuneration per worker in the private sector index 2000 = 100 } \\
\text { Remuneration per worker in the private sector 4-term \% change }\end{array}$ & $\mathrm{l}$ & 1 \\
\hline 241 & $\begin{array}{l}\text { Remuneration per worker in the private sector 4-term \% change at } \\
\text { constant prices }\end{array}$ & $\mathrm{nl}$ & 0 \\
\hline 242 & $\begin{array}{l}\text { Total remuneration per worker constant 2000 prices. Index } \\
\text { 2000 } 100\end{array}$ & $\mathrm{l}$ & 0 \\
\hline 243 & Total remuneration per worker index 2000 = 100 & $\mathrm{l}$ & 1 \\
\hline 244 & Total remuneration per worker 4-term \% change & $\mathrm{nl}$ & 0 \\
\hline 245 & Total remuneration per worker 4-term \% change at constant prices & $\mathrm{nl}$ & 0 \\
\hline
\end{tabular}

Nota bene: Integrated of order $0=0$ and $1=1$; not integrated of order $1=$ NS; natural $\log$ variables $=1$; no transformation $=$ nl.

\section{References}

Bai, J., Ng, Serena. 2007. Determining the number of primitive shocks in factor models, Journal of Business and Economic Statistics 25, 52-60.

Bai, J., Ng, Serena. 2002. Determining the number of factors in approximate factor models, Econometrica 70, 191-221.

Banbura, M., Gianonne, D., Reichlin, L. 2008. Bayesian VARs with Large Panels, European Central Bank, p. 966. Working Paper.

Bernanke, B.S., Gertler, M. 1995. Inside the black box: the credit channel of monetary policy transmission, The Journal of Economic Perspectives 9, 27-48.

Bernanke, B.S., Mihov, I. 1998. Measuring monetary policy, Quarterly Journal of Economics 113, 869-902

Bernanke, B.S., Gertler, M. 1999. Monetary policy and asset volatility, Federal Reserve Bank of Kansas City, Economic Review 84, 17-52.

Bernanke, B.S., Boivin, J., Eliazs, P. 2005. Measuring the effects of monetary policy: a factor augmented vector autoregressive (FAVAR) approach, The Quarterly Journal of Economics 120, 387-422. 
Borio, C.E.V., Kennedy, N., Prowse, S.D. 1994. Exploring aggregate asset price fluctuations across countries: measurement, determinants, and monetary policy implications, Bank for International Settlements. Economics Paper No. 40.

Burger, P., Van Rensburg, L.J. 2008. Metropolitan house prices in South Africa: do they converge?, South African Journal of Economics 76, 291-297.

Case, K., Shiller, R., Quigley, J. 2005. Comparing wealth effects: the stock market versus the housing market, Advances in Macroeconomics 5, 1-32.

Das, S., Gupta, R., Kabundi, A. 2008. Is a DFM well-suited for forecasting regional house price inflation?, Economic Research Southern Africa.Working Paper No. 85.

Das, S., Gupta, R., Kabundi, A. forthcoming. Could we have forecasted the recent downturn in the South African housing market? Journal of Housing Economics. doi:10.1016/j.jhe.2009.04.004.

Das, S., Gupta, R., Kabundi, A. 2009. Forecasting Real House Price Growth in the Nine Census Divisions of the US. Department of Economics, University of Pretoria. Working Paper No. 200902.

Forni, M., Hallin, M., Lippi, M., Reichlin, L. 2000. The generalized dynamic factor model: identification and estimation, Review of Economics and Statistics 82, 540-554.

Fry, R., Pagan, A. 2007. Some Issues in Using Sign Restrictions for Identifying Structural VARs, NCER Working Paper Series. Working Paper No. 14.

Gupta, R., Das, S. 2008. Spatial Bayesian methods in forecastiong house prices in six metropolitan areas of South Africa, South African Journal of Economics 76, 298-313.

Iacoviello, M. 2002. House prices and business cycles in Europe: a VAR analysis, Department of Economics, Boston College. Working Paper No. WP540.

Iacoviello, M. 2005. House prices, borrowing constraints, and monetary policy in the business cycle, American Economic Review 95, 739-764.

Iacoviello, M., Minetti, R. 2003. Financial liberalisation and the sensitivity of house prices to monetary policy: theory and evidence, The Manchester School 71, 20-34.

Iacoviello, M., Minetti, R. 2008. The credit channel of monetary policy: evidence from the housing market, Journal of Macroeconomics 30, 69-96.

Iacoviello, M., Neri, S. 2008. Housing Market Spillovers: Evidence from an Estimated DSGE Model, Boston College Department of Economics. Working Paper No. 659.

Kasai, N., Gupta, R. 2008. Financial Liberalization and the Effectiveness of Monetary Policy on House Prices in South Africa, Department of Economics, University of Pretoria.Working Paper No. 200803.

Kilian, L. 1998. Small-sample confidence intervals for impulse response functions, Review of Economics and Statistics 80, 218-230.

Ludi, K., Ground, M. 2006. Investigating the Bank Lending Channel in South Africa: A VAR Approach, Department of Economics, University of Pretoria. Working Paper No. 200604.

McCarthy, J., Peach, R. 2002. Monetary policy transmission to residential investment, Economic Policy Review 139-158.

Rapach, D.E., Strauss, J.K. 2007. Forecasting real housing price growth in the Eighth District States. Federal Reserve Bank of St. Louis, Regional Economic Development 3, pp. 33-42.

Rapach, D.E., Strauss, J.K., 2009. Differences in housing price forecast ability across U.S. states. International Journal of Forecasting 25, 351-372.

Sims, C. 1992. Interpreting the macroeconomic time series facts: the effects of monetary policy, European Economic Review 36, 975-1000. 
Stock, J.H., Watson, M.W. 1998. Diffusion Indexes, National Bureau of Economic Research. Working Paper No. 6702.

Stock, J.H., Watson, M.W. 2002. Macroeconomics forecasting using diffusion indexes, Journal of Business and Economic Statistics 20, 147-162.

Stock, J.H., Watson, M.W. 2003. Forecasting output and inflation: the role of asset prices, Journal of Economic Literature 41, 788-829.

Stock, J.H., Watson, M.W. 2004. Combination forecasts of output growth in a seven-country data set, Journal of Forecasting 23, 405-430.

Uhlig, H. 2005. What are the effects of monetary policy on output? Results from an agnostic identification procedure, Journal of Monetary Economics 52, 381-419.

Vargas-Silva, C. 2008. Monetary policy and the US housing market: a VAR analysis imposing sign restrictions, Journal of Macroeconomics 30, 977-990.

Vargas-Silva, C. 2008. The effect of monetary policy on housing: a factor-augmented vector autoregression (FAVAR) approach, Applied Economics Letters 15, 749-752.

Walsh, C.E. 2000. Monetary Theory and Policy, Massachusetts, The MIT Press, Cambridge.

\section{Notes}

${ }^{1}$ Data on house prices are obtained from the ABSA Housing Price Survey, with ABSA being one of the leading private banks of South Africa. The ABSA Housing Price Survey, distinguishes between three price categories as - luxury houses (R2.6 million to R9.5 million), middlesegment houses (R226,000 to R2.6 million) and affordable houses (R226,000 and below with an area in the range of $40 \mathrm{~m}^{2}-79 \mathrm{~m}^{2}$ ); and further subdivides the middle-segment category based on the square meters of house area into small $\left(80 \mathrm{~m}^{2}-140 \mathrm{~m}^{2}\right)$, medium $\left(141 \mathrm{~m}^{2}-220 \mathrm{~m}^{2}\right)$ and large $\left(221 \mathrm{~m}^{2}-400 \mathrm{~m}^{2}\right)$.

${ }^{2}$ See Section 2 for further details.

${ }^{3}$ Note, besides the empirical part of the paper, Iacoviello and Minetti (2003) uses a calibrated Dynamic Stochastic General Equilibrium (DSGE) model to analyze the impact of monetary policy on house prices. More recently, Iacoviello and Neri (2008) used a more elaborate estimated DSGE model for this purpose. However, the model is restricted in the sense that it used only 10 macroeconomic variables including only a few housing market variables.

${ }^{4}$ The home price puzzle occurs when the home price increases, instead of declining, following a contractionary monetary policy.

${ }^{5}$ As will be seen below in Section 2, the FAVAR model nests a simple VAR. Given this, when we estimated the VAR model comprising of the real house price growth rates of the five categories and the interest rate measure, using our data set, as in Kasai and Gupta (2008), we too observed the prevalence of the home price puzzle for not only the large-, medium- and smallmiddle-segment housing, but also for affordable housing. These results are available upon request from the authors.

${ }^{6}$ This paper follows the econometric framework of the FAVAR model described in Bernanke et al. (2005).

${ }^{7}$ Note, once the factors are estimated, other identifying procedures like those of (Bernanke and Mihov, 1998) and (Uhlig, 2005) can be also be applied for identifying innovations. However, as recently shown by Fry and Pagan (2007), there is no reason to believe that sign restrictions will 
generate better quantitative estimates of the effects of shocks than the recursive identifying scheme. The fact that additional structure might not be empirically supported by the data, refer to the results of the Bayesian estimation of the model, reported in footnote 14 .

${ }^{8}$ Please refer to Ludi and Ground (2006) for further details.

${ }^{9}$ Details about the data and the statistical treatment of the variables used to estimate the FAVAR are reported in Appendix A of the paper.

10 The choice of 4 lags is based on the unanimity of the AIC and FPE criterion. In addition, given that there is ample evidence that monetary policy takes about a year or longer to affect the economy, the choice is not unjustified. Keeping in line with this argument, our results remain qualitatively the same with 3 lags.

${ }^{11}$ Using sub-samples covering the periods of 1980:01-1994:04 and 1995:01-2006:04 to account for the change in political regime in South Africa in the year 1994, with the exception of the small-middle-segment housing which was seen to experience an insignificant short-lived increase in the real house price growth rate for a quarter or so, no evidence was found for the home price puzzle.

${ }^{12}$ As in Bernanke et al. (2005), the FAVAR model was also estimated using likelihood-based Gibbs sampling techniques. However, the results indicated exceptionally wide confidence bands implying the imprecision involved in the parameter estimates. In addition, we also observed the prevalence of the home price puzzle in all the categories, baring the medium-middle-segment housing. This is, perhaps, an indication of the Bayesian approach imposing additional structure, not supported empirically by the data. Given this, the results have not been reported. They are, however, available upon request.

The views expressed herein are those of the authors and do not necessarily reflect the views of the Bank of England. We would like to thank an anonymous referee for many helpful comments.

Corresponding author. Tel.: +27115592061 ; fax: +27 115593039. 